Artículo de investigación

Cómo citar: Mesa, W. (2019).

Genealogía de la organización

de presos políticos en Colombia,

Polisemia, 15(28), 3-23.

http://doi.org/10.26620/uniminuto.

polisemia.15.28.2019.3-23

ISSN: $1900-4648$

elSSN: 2590-8189

Editorial: Corporación Universitaria Minuto de Dios - UNIMINUTO

Recibido: 5 de julio de 2019

Aceptado: 15 de agosto de 2019

Publicado: 25 de octubre de 2019

\title{
Genealogía de la organización de presos políticos en Colombia
}

\author{
Genealogy of political prisoners' \\ organization in Colombia
}

\author{
Genealogia da organizaçãode \\ prisioneiros políticos na Colômbia
}

\section{Resumen}

La temática sobre presos políticos en Colombia ha sido mínimamente analizada, no solo por la precariedad en términos bibliográficos, sino por el aislamiento, el encierro y el sometimiento carcelario en el que están inmersos. En efecto, desde finales de la década de 1970 y debido al contexto político de la lucha contra el comunismo, los efectos del Frente Nacional, el estado de sitio, el impacto del estatuto de seguridad nacional de 1978, así como el intento de consolidación de las organizaciones político-militares en el país y las movilizaciones sociales, fueron determinantes en el flujo de líderes sociales, políticos y guerrilleros que llegaron a las cárceles, lo que posibilitó formas de organización que estuvieron insertas en la dinámica nacional. Esas primarias formas de organización son analizadas desde su surgimiento en 1977 hasta la amnistía de 1982, en componentes como la solidaridad, la creación de comités de familiares, la toma a la embajada Dominicana por la guerrilla del M-19 y la coordinación de presos de diferentes vertientes ideológicas y organizativas.

Docente de la Escuela de

Ciencias Sociales, Artes y

Humanidades. Universidad

Nacional Abierta y a Distancia.

UNAD. Doctorando en Estado

de Derecho y Gobernanza

Global. Universidad de

Salamanca. Magister

en Investigación Social

Interdisciplinaria. Universidad

Distrital. Licenciado en

Ciencias Sociales. Universidad

La Gran Colombia.

william.mesa@unad.edu.co

Palabras clave: presos políticos, organización política, solidaridad, cárceles colombianas, guerrillas.

\begin{abstract}
The political prisoners are a topic that has been slightly analyzed, not only because of the lack of bibliography but also because of the isolation, the enclosure and warden subjugation. In effect, since the last part of the decade of 1970 and due to the political context of the fight against communism, the aide effects of the National Front, the state of siege, the impact of the National Security Statute of 1978, just as the attempt of consolidation of Army-political
\end{abstract}


organizations in the country and social demonstrations were determining in the flow of social leaders, politicians and guerrilleros who arrived to prison, making possible some ways of organization inserted in the national dynamics. Those basic ways of organization are analyzed since they emerged in 1977 until the amnesty of 1982 in topics such as solidarity, the creation of family comities, the occupation of the Dominican Embassy by M-19 and the coordination of prisoners from different ideological and organizational aspects.

Keywords : political prisoners, political organization, solidarity, colombian prisons, guerrillas.

\section{Resumo}

A questão dos presos políticos na Colômbia foi minimamente analisada, não só devido à precariedade em termos bibliográficos, mas também devido ao isolamento, confinamento e subjugação prisional em que estão imersos. De facto, desde o final dos anos 70 e devido ao contexto político da luta contra o comunismo, os efeitos da Frente Nacional, o estado de sítio, o impacto do Estatuto de Segurança Nacional de 1978, bem como a tentativa de consolidação das organizações político-militares no país e as mobilizaçóes sociais, foram decisivas para o fluxo de líderes sociais, político e de guerrilha que chegaram às prisóes, o que tornou possíveis formas de organização que foram inseridas na dinâmica nacional. Estas formas primárias de organização são analisadas desde o seu aparecimento em 1977 até à amnistia de 1982, em componentes tais como a solidariedade, a criação de família, a apreensão da embaixada dominicana pela guerrilha M-19 e a coordenação de prisioneiros de diferentes origens ideológicas e organizacionais.

Palavras-chave: prisioneiros políticos, organização política, solidariedade, prisóes colombianas, guerrilhas. 


\section{Introducción}

Los presos políticos ${ }^{1}$ han sido una parte invisibilizada en el conflicto armado colombiano, sufren no solo del sometimiento carcelario producto de la afirmación de sus convicciones y acciones políticas, sino del abandono histórico y político del que han sido víctimas en las últimas décadas, incluso por sus propias organizaciones. En efecto, al interior de las cárceles colombianas la participación de los presos políticos ha convertido los muros y las rejas en nuevas trincheras y escenarios de confrontación al orden social, como espacios de resistencia a la falsa resocialización, a las torturas y los aislamientos que han sido una constante como medida correctiva judicial, política y militar para derrotarlos física, psicológica y moralmente.

En esa medida, el presente artículo tiene como objetivo analizar las primeras formas organizativas de presos políticos desde finales de 1970 hasta mediados de 1980 cuyo contexto político, social y cultural se veía relacionado con grandes convulsiones políticas, tanto de la estructura hegemónica estatal como el fortalecimiento de las organizaciones sociales emergentes, y evidentemente el accionar de varias guerrillas en el país.

La investigación desarrolla aspectos centrales de la organización de presos, inicia con un contexto internacional, donde se referencian dos colectivos de presos, uno español y el otro chileno. A la par establece un marco bibliográfico en el cual se plantea la relación de la información bibliográfica, parte del contexto político colombiano, así como el impacto del estatuto de seguridad en la tipificación de preso político, el manejo general de los detenidos y el contexto represivo en el período de análisis. A partir de esto se intentará resolver el planteamiento problemático de la investigación, que parte de la pregunta: ¿qué tipo de organizaciones de presos políticos surgieron en las cárceles colombianas, cómo fluctuaban sus relaciones de poder y qué incidencia tuvieron en el contexto político nacional.

\section{Organizaciones de presos en otros países como campo de estudio}

En el marco internacional, los procesos de organización política al interior de las cárceles permiten establecer un marco de experiencias significativas,

1 Definidos como sujetos que han sido encarcelados por motivos políticos. Entre esta categoría se pueden vislumbrar tres clases de presos políticos sin ninguna jerarquización para su orden. Se encuentran en primer lugar líderes sociales, campesinos, sindicales o de organizaciones comunitarias, docentes y estudiantes, que por su accionar político contra el sistema hegemónico son detenidas. En segundo lugar están aquellos que son militantes de organizaciones políticomilitares o guerrillas, los cuales también son conocidos como presos de guerra, y debido al factor político, de oposición están insertos de manera directa en la definición. Finalmente y en tercer lugar se encuentran sujetos que por su labor política, cívica o social son asociadas y vinculadas con organizaciones político-militares con el fin de desvirtuar o deslegitimar su trabajo político, y son considerados falsos positivos judiciales, como una forma en que el sistema judicial y militar demuestra metas y objetivos. 
susceptibles de evidenciar que a pesar del encierro y el sometimiento carcelario, diferentes formas de asociación política, permiten vehiculizar luchas, propender por el mejoramiento de condiciones específicas como la salud, la educación, el régimen de visitas, entre otros. Se encuentran en el escenario dos organizaciones que permiten ir delimitando el campo de estudio, por un lado está la Coordinadora de Presos en Lucha (Copel) en España y por el otro el denominado Kolectivo Kamina Libre en Chile.

\section{Coordinadora de presos en lucha (Copel)}

La Copel es una organización que emerge y establece su acción política durante la llamada transición española, entre 1975 y 1978 en los diferentes centros penitenciarios españoles. El surgimiento de la Copel tiene como condiciones carcelarias el sometimiento extremo, traducido en torturas físicas, psicológicas, aislamientos sensoriales ${ }^{2}$, como producto de la estructura penitenciaria de la dictadura instalada desde 1939 tras finalizar la guerra civil española. De otra parte se encuentra el contexto de la muerte del dictador Francisco Franco y la creación del indulto general decretado en 1975, concedido únicamente para los denominados presos políticos ${ }^{3}$. Por esta razón, el restante de presos ${ }^{4}$ excluidos del indulto y juzgados por el mismo aparato de la dictadura, iniciaron una serie de actividades de tipo organizativo y propiciaron acciones conjuntas en todo el país. Cabe resaltar en este campo, que gran parte de los presos que no habían sido parte del indulto se declaraban simpatizantes o militaban en algún tipo de organización anarquista 5 .

Entre las acciones más destacadas de la organización se pueden resaltar huelgas, motines, toma de tejados de forma coordinada, asambleas y el crecimiento continuo de estas expresiones hacia otras cárceles (Galvan, 2007).

A partir de la creación de la coordinadora comienza un ciclo de protestas que conducirá, por un lado, a la consolidación del núcleo original y, por otro, a la difusión de la problemática de los presos sociales más allá de los muros de las prisiones. Durante este periodo, la Copel incrementa sus respaldos, especialmente entre los presos de Madrid, donde reside el núcleo fundador, pero también inicia, al cabo de poco tiempo, su expansión hacia otras prisiones, adonde, como La Modelo de Barcelona, llegaron presos portadores de noticias provenientes de Carabanchel.

2 Privación de la vista o desorientación.

3 La acepción de preso político en el marco de este indulto precisaba de activistas de los partidos opositores; socialdemócratas, socialistas y comunistas.

4 Denominados también como presos sociales o comunes, son aquellos que en el contexto de la transición no tenían delitos directamente políticos y jurídicamente estaban tipificados en el orden del delito común.

5 Es fundamental en este punto, insistir en la influencia del anarquismo en España y con precisión, en el desarrollo de la guerra civil española, que reflejó un proceso de organización horizontal, asambleario, y capaz de ofrecer una resistencia histórica tanto al fascismo, como a los procesos de resistencia armada y política durante los años de la transición franquista. En tanto anarquistas, no confluían con las organizaciones verticales tipo partido político, establecían formas de acción directa a través de organizaciones sindicales (anarcosindicalismo) y organizaciones sociales en general, por lo cual, los anarquistas en su gran mayoría no serian indultados. 
El proceso mismo de la organización de la Copel estaba determinado por comisiones de trabajo o también llamadas "células" clandestinas, difuminadas en las cárceles españolas, cuyo número de activistas, dependía de los presos articulados a la coordinadora en cada prisión. Gestionaban debates, asambleas generales, formas de movilizar la información entre cárceles (Copel y APRE, 1977). La organización Copel fue apoyada por una gran cantidad de movimientos sociales al exterior de la prisión, desde comités de abogados, sindicatos, comités estudiantiles, hasta comités de barrio, lo que potenció su fuerza y lucha al punto de desembocar en formas organizativas específicas fuera de la prisión como la Asociación de Familiares y Amigos de Presos (Afape).

Se constituye también una imprenta rudimentaria mediante la cual y de manera artesanal, se editaban textos cortos, los cuales eran enviados en los traslados de presos:

Empezamos con unos niveles muy rudimentarios, escribiendo panfletos minúsculos, en letra muy pequeña, que escondíamos, para difundirlos aprovechando los traslados, en los dobladillos de los pantalones, en las fundas de los dientes, en los lugares más inverosímiles para que llegase la agitación al resto de las cárceles del Estado (Pont, 2008, p. 148).

Cabe resaltar que la movilidad de estos comunicados era funcional para la denuncia de torturas, golpizas y condiciones particulares de las cárceles, desconocidas para la población en general. De otra parte, en los lineamientos de la coordinadora asumían la fuga como medio de acción directa en busca de la libertad.

Para el 18 de julio de 1978 se convocó a una huelga general en las prisiones españolas, en esa fecha se cumplían 43 años del inicio de la guerra civil española, lo que generó una pluralidad de acciones: motines, protestas, huelgas, tomas de tejado, laceraciones colectivas ${ }^{6}$. Estas acciones duraron 4 días y debido a los enfrentamientos, sería recordada como la "batalla de Carabanchel".

En este periodo, se inició un proceso de desarticulación de la Copel, primero con la elaboración de la nueva ley penitenciaria, que por un lado mantenía a nivel institucional un discurso de concertación debido a la presión política del exterior, pero en términos prácticos inició una serie de procedimientos para eliminar la coordinadora. Se procedió a su desarticulación en este año, los líderes fueron confinados en la sexta galería de la cárcel de Carabanchel, caracterizada por las torturas, las golpizas y los aislamientos; se recrudeció el hacinamiento y se mezclaron menores en las prisiones, lo que hizo imposible la organización de base, sumado al hostigamiento constante, la creación de grupos al interior de las cárceles llamados "anticopel" y que funcionaban como delatores, rompehuelgas; además se utilizaron métodos adversos como instigación al robo, violencia y drogadicción, traslados masivos, entre otros (Pont, 2008).

6 Autolesiones en la muñeca. 
El desdoblamiento represivo que se sufrió al interior, sumado a la creación y puesta en funcionamiento de la cárcel de alta seguridad "Herrera de la Mancha", donde se estableció un régimen de tortura constante, influyó en el aniquilamiento paulatino de este proceso organizativo.

\section{Kolectivo Kamina Libre ${ }^{7}$}

Surge inicialmente de una disidencia del colectivo de presos políticos de la guerrilla Mapu Lautaro, estructura político militar que se activó contra la dictadura de Augusto Pinochet desde los años ochenta. Se trataba de una guerrilla de corte marxista-leninista, que reprodujo las formas de asociación y mando al interior de las cárceles con sus militantes. Por ende, las relaciones verticales, jerárquicas, así como el centralismo en la toma de decisiones eran una constante en el funcionamiento de este colectivo al interior de la cárcel.

Algunos de sus militantes presos, queriendo generar procesos diferentes y alternativos de organización, que no mantuvieran la lógica centralista y verticalista, formularon nuevas dinámicas de asociación:

Una vez encarcelada toda la dirección del Mapu Lautaro, las órdenes ya no vendrían desde "afuera", sino, que la cabeza jerárquica se encontraba al interior de la cárcel, al igual que la mayor parte de sus militantes. Sin embargo, las diferencias de poder continuaron al interior de la organización, la toma de decisiones siguió siendo monopolio de la dirección, tanto las que afectaban la vida y práctica de los militantes encarcelados, como los que se encontraban en "libertad". El hecho de encontrarse en prisión, militantes y dirección política de la organización, comenzó a causar, poco a poco, discrepancias en la manera de llevar a cabo el "problema de la prisión" y al rol que se le otorgaba a ésta en el proceso que se vivía afuera de ella (Solar, 2007, p. 45).

La cárcel de Santiago fue el epicentro de este proceso organizativo del Kamina Libre entre 1995 y 1996, período en que en efecto, la dictadura de Pinochet había cesado. Sin embargo el aparato judicial mantenía dispositivos de la dictadura, lo que influyó en que el accionar de las guerrillas y de las organizaciones políticas continuara, y con ello los efectos represivos aumentaron, afuera como y al interior de las cárceles.

Divergencias con el mando dela Mapu Lautaro, asícomo transformaciones importantes en el campo político-organizativo, dio como resultado la creación del Kolectivo desde una perspectiva anarquista y autónoma. Entre los elementos ideológicos de transformación, se asumió como parte elemental la asamblea, la autogestión, la acción libertaria, la construcción política horizontal, una visión anticarcelaria y anticapitalista, entre otras (Solar, 2007, p. 48).

7 La utilización de la letra $\mathrm{K}$ en vez de la C, lo establece la propia organización en los siguientes términos: "(...) es una consonante velar, explosiva y sorda; es genuina del idioma mapuche. Suena muy fuerte culturalmente. En el mapudungún no existe ni la " $c$ " ni la " q" españolas. La utilización de esta letra, entre otras es una abierta manifestación "Kontrakultural". (Periódico Libelo, 1998). 
El Kamina Libre, inició además procesos artísticos dentro de la prisión, crearon nuevas dinámicas entre lo icónico y lo político, rompieron con la estética de las guerrillas y de los colectivos de presos, y esto se convirtió en una forma de evidenciar la pugna contra la autoridad. El grupo participó de huelgas de hambre, creación de medios de información al interior de la prisión, así como del mantenimiento de un discurso combativo y subversivo, apoyado en cierta medida desde una concepción contracultural, que les permitió desdoblar trabajo político fuera de las cárceles con colectivos anarquistas y grupos musicales, que a su manera de comprender, buscaban una forma de crítica al sistema cultural hegemónico, de allí su apoyo constante por parte de grupos punk, hardcoreros, ocupas, comités de presos, etc. (Entrevista al Colectivo de prisioneros políticos Kamina Libre. 2006).

Ciertamente, el aporte de este proceso organizativo surge en la medida en que se desajusta de la organización partidista, común en los centros de reclusión y los colectivos de presos, así como las transformaciones teóricas y estéticas que fueron parte del trabajo del Kamina: críticas al sentido de la "libertad" determinado por el afuera y el adentro carcelario, sin tener en cuenta el contexto del capitalismo, modificaciones en el orden de la comunicación, transformaciones en la toma de decisiones, entre otros. El grupo se autoliquidó en el 2003, se entendió el proceso como parte fundamental de las luchas anticarcelarias, pero bajo la imposibilidad de seguirlo manteniendo.

\section{Contexto bibliográfico}

La información bibliográfica sobre la historia de organizaciones de presos políticos en Colombia a partir de la segunda década del siglo XX es precaria, y lo es más aún cuando se trata de examinar el tipo de asociaciones políticas que emergieron: proceso de constitución, relacionamientos de poder, acciones políticas al interior de la cárcel, rupturas, acciones colectivas, entre otros.

La dificultad para lograr sistematizar el proceso de organización durante las primeras décadas del conflicto armado colombiano se debe a la mínima existencia de organizaciones de defensa o de solidaridad con los detenidos políticos. En el tema carcelario, la Fundación Comité de Solidaridad con Presos Políticos (FCSPP) es la primera organización de este estilo nacida a principios de $1973^{\circ}$. El nacimiento de la FCSPP fue fundamental para

8 Así lo narra Enrique Santos Calderón para el periódico El Tiempo: "García Márquez acababa de recibir otro premio literario con 10.000 dólares (de la Universidad de Arizona) y quería consejos sobre a quién donarle esa plata en Colombia para evitar una nueva 'escandola'. Me sentí halagadísimo cuando el ya famoso autor de Cien años de soledad, con el que nunca había cruzado palabra, me llamó a preguntarme si lo indicado sería entregársela a alguna asociación de presos políticos. Cuando le dije que aquí no existía una entidad de esa índole, me dijo con su desparpajo Caribe: "Pues fúndala, no joda, invéntatela". Asumí la complicada consigna, que significó convencer a media docena de escépticos líderes sindicales y campesinos, y así nació el Comité de Solidaridad con los Presos Políticos. Y, poco después, la revista Alternativa" (Santos, 2011). 
generar una narrativa histórica de las organizaciones carcelarias, aparte del acompañamiento jurídico-político y orgánico que esta prestaba a los presos políticos. El contexto de su nacimiento se enmarca en la detención de varios dirigentes sindicales, -principalmente de la Unión Sindical Obrera (USO), la detención de líderes sociales y el aumento significativo de las acciones guerrilleras.

De hecho, es este comité el que edita dos textos fundamentales sobre la reconstrucción de formas organizativas de carácter político en el interior de las prisiones. Por un lado edita El libro negro de la represión ${ }^{9}$, de los autores Jorge Villegas y Gerardo Rivas, libro que constituye un trabajo de recopilación sobre los diferentes hechos generados en el período conocido como Frente Nacional, en el que se teje de manera cronológica diferentes testimonios, documentos y archivos entre 1958 y 1980. Este primer texto permite identificar los efectos del bipartidismo ya hegemónico en la historia colombiana (liberalismo-conservadurismo) desde el Frente Nacional, que divide el aparato estatal, sea a través de los gabinetes ministeriales o la presidencia de la República y evidencia un contexto de exclusión de otros sectores políticos y sociales (Paredes y Díaz, 2007, p. 189).

De otra parte, el contexto político-social entre 1970 y 1980, fue muy convulsionado, fundamentalmente por la influencia de la guerra fría y la lucha contra el comunismo. Con el gobierno de Alfonso López Michelsen (1974-1978) se reprodujeron las mismas lógicas del Frente Nacional, en lo que tenía que ver con la repartición de cargos burocráticos. Mediante el Decreto Legislativo 1136 del 12 de junio de 1975 se declaró el estado de sitio, en el cual se contemplaba que los delitos que fuesen cometidos a partir de la expedición del Decreto, eran atribuidos a la jurisdicción penal militar, por lo cual, varias luchas sindicales o campesinas fueron criminalizadas y sus líderes, juzgados como guerrilleros en consejos verbales de guerra (Restrepo, 2017).

Con el gobierno del presidente Julio Cesar Turbay (1978-1982), los procesos de represión se profundizan, debido al impacto del denominado estatuto de seguridad, definido como un "instrumento de carácter político-jurídico-militar", que tuvo fuertes repercusiones contra los derechos humanos, contra la legitimidad del sistema político colombiano, la desmedida represión a los movimientos sociales, el aumento de operaciones contrainsurgentes, lo que efectivamente tuvo repercusiones en el engrosamiento de presos de carácter político en las cárceles del país:

Se restringieron las garantías procesales de defensa al momento de la detención y en el allanamiento de inmuebles, así como la garantía al debido proceso, especialmente en las sentencias que dictaban los comandantes del Ejército, que en la atribución de nuevas competencias, juzgaron acciones colectivas como manifestaciones, huelgas, paros como si fueran delitos de tipo político. Por último, se entregó a la Policía Nacional la sanción del delito de la contravención al orden público, que al no ser definido de forma precisa fue objeto de múltiples interpretaciones (Jiménez, 2009, p. 89)

9 Primera edición hasta 1974, segunda edición ampliada hasta 1980. 
Con el estatuto de seguridad se estableció un proceso de militarización del aparato judicial bajo los principios de la seguridad nacional, que tejían en términos ideológicos un enemigo interno, con la creación de los mecanismos jurídicos que desde la excepcionalidad, limitaba y criminalizaba las acciones de protesta, censuraba todo tipo de información que estaba en contra del Estado, también precarizaba las garantías sociales y minimizaba los derechos individuales, como forma de combatir la oposición política (Presidencia de la República, artículo 4 y 13).

Probablemente, el artículo 2 del estatuto es el que más represente la definición de detenido o preso político, regulado de la siguiente manera:

Los que promuevan, encabecen o dirijan un alzamiento en armas para derrocar al Gobierno Nacional, legalmente constituido, o para cambiar o suspender en todo o en parte el régimen constitucional existente, en lo que se refiere a la formación, funcionamiento o renovación de los poderes públicos u órganos de la soberanía, quedarán sujetos a presidio de ocho a catorce ańos y a la interdicción de derechos y funciones públicas por el mismo tiempo.

Los que simplemente tomen parte en la rebelión, como empleados de ella con mando o jurisdicción militar, política o judicial, quedarán sujetos a las dos terceras partes de las sanciones indicadas en el inciso anterior. Los demás individuos comprometidos en la rebelión incurrirán en las mismas sanciones, disminuidas en dos terceras partes (Presidencia de la República, 1978).

Con el estatuto, varias organizaciones sociales fueron estigmatizadas, otras disueltas, sus líderes encarcelados y juzgados como guerrilleros, mientras que a las principales estructuras político-militares como las FARC, el EPL, el ELN y el naciente $\mathrm{M}-19^{10}$, las atacaron con acciones ofensivas que desmantelaban sus bases sociales y bajo captura, procedían a realizar torturas y violaciones a sus derechos humanos y fundamentales (Pecaut, 1997). De allí parte, que los detenidos por motivaciones políticas, eran conducidos a los centros de reclusión donde confluían presos por delitos comunes, solo hasta determinadas condiciones -fundamentalmente por detenciones masivas-, y es que la cantidad de presos políticos y su influencia resalta por su organización, lo que se evidenciará en los siguientes apartados.

En este contexto surge el segundo texto preponderante para la investigación, titulado Desde adentro, de los autores María Tila Uribe y Francisco Trujillo, quienes fueron presos políticos al finalizar la década de 1970 (Uribe y Trujillo, 1984). Este libro probablemente constituye uno de los primeros escritos desde el interior de la prisión con el objetivo de hacer una narrativa a modo de diario de las condiciones carcelarias, y un relato de las primeras formas de organización de los presos políticos.

10 En su orden, Fuerzas Armadas Revolucionarias de Colombia, Ejército Popular de Liberación, Ejército de Liberación Nacional, Movimiento 19 de abril. 


\section{La solidaridad como componente organizativo}

En primera instancia, es necesario hacer referencia a ciertas prácticas ya establecidas por los presos políticos, entre las cuales se encontraban; el estudio individual, los cánticos, las tertulias, el tejido y otras actividades mediante las cuales lograban tener una cotidianidad carcelaria con menores niveles de sometimiento. Según la narrativa de Uribe y Trujillo (1984), para el año 1977 el principal centro penitenciario donde recluían presos de carácter político era la cárcel La Modelo en Bogotá, en la cual se encontraban unos 35 presos políticos, mientras que en el resto de cárceles:

(...) en calidad de sumariados, había aproximadamente otros 100 y en condición de condenados unos 60 más. En total unos 200 presos políticos, de quienes muy poco se hablaba. La opinión pública estaba desinformada. Después descubriríamos que había muchos más presos políticos, de largos años de prisión, olvidados totalmente, además de cientos de presos sociales, vinculados cercanamente a las luchas populares. (Uribe y Trujillo, 1984, p. 192).

Las prácticas de los presos políticos y cierta identificación interna entre líderes sociales y guerrilleros, permitió que se generaran los primeros lazos de fraternidad, tanto de los casos específicos jurídicos y políticos, como de los primeros indicios de fomentar procesos de colaboración y ayuda mutua, y es la solidaridad el potenciador inicial de las primeras formas organizativas.

En 1977 la cárcel La Modelo en Bogotá era visitada no solo por familiares, amigos y compañeros de los detenidos políticos, sino que a su vez, confluían estudiantes universitarios, quienes semanalmente contribuían con cuotas económicas para los presos, aplicadas a la ración alimentaria carcelaria, lo cual hizo emerger determinadas formas de administración grupal de esos dineros, primeras distribuciones de trabajos o actividades colectivas, y con ello el inicio de reflexiones grupales sobre elementos como la cooperación, disciplina y responsabilidad (Uribe y Trujillo, 1984).

Se debe resaltar en este aspecto, que tanto las raciones alimentarias como los elementos de aseo eran precarios en la cárcel. Debido a esto, existían despensas donde se vendían este tipo de elementos bajo el control de "caciques" (presos de influencia económica o con algún tipo de control o poder al interior), así como negociantes (es decir comerciantes), lo que significaba por un lado, mantener cierta dinámica de dominación con presos que no podían adquirirlos y por el otro lado, cobros excesivos. En efecto, las contribuciones económicas así como materiales que efectuaban tanto los familiares como los solidarios con los detenidos políticos, les permitían constituir sus propias despensas y administrarlas de forma colectiva.

Más tarde, tras llegar otras ayudas, nuestra organización se extendió al almuerzo para el que cada uno tenía asignada una modestísima suma. Éramos unos 30, pues había llegado al patio otro grupo de detenidos políticos, casi todos estudiantes. Resolvimos entonces preparar desayunos y almuerzos, vendiendo parte de ellos a otros detenidos. Eso sí - dijo la mayoría de los compañeros- sin que haya especulación, a mejores precios de los que venden los negociantes. (Uribe y Trujillo, 1984, p. 192). 
Además de esto, el estudio colectivo contemplaba la posibilidad del debate y la discusión no solo teórica o doctrinaria a nivel ideológico, sino que permitía la unificación de conceptos y necesidades, situación que amenizaba las conversaciones. Para tal efecto, los grupos de estudio se establecían principalmente en un horario de $6 \mathrm{pm}$ a $8 \mathrm{pm}$. Con esta dinámica grupal, se fortalecían los lazos entre presos políticos, y estos con los detenidos comunes. La delación, que era una práctica constante entre los presos comunes, fue minimizándose en la medida en que la confianza, y la auto-referenciación como presos políticos, posibilitaban la empatía, el trabajo conjunto, la defensa grupal y la solidaridad.

Efectivamente, el estudio colectivo permitió una mayor referenciación social y política, pero también reconfiguró situaciones de autoreferenciación, -autodenominación de preso político- puesto que por temas de seguridad o por estrategia de defensa judicial, constituía una dificultad inicial para un posible proceso organizativo.

Las diferentes actividades permitieron que los presos políticos y su respectivo trabajo se permeara de cierta visibilización, lo que provocó simpatías, toda vez que confluyó en contrarrestar los procesos de dominación y control que ejercían algunos presos, así como generar métodos defensivos contra posibles agresiones de la guardia del penal ${ }^{11}$. De esta manera la organización se constituyó también como método defensivo y elemento de fuerza ante estas problemáticas (Uribe y Trujillo, 1984).

De otra parte, un evento externo fue significativo en la consolidación organizativa de los presos al interior de las cárceles colombianas; el paro cívico de 1977. Dicho paro fue iniciado el 14 de septiembre y es considerado uno de los levantamientos populares más importantes del siglo XX en el país.

El paro cívico del 14 de septiembre fue convocado por las cuatro centrales sindicales de la época: CTC, UTC, CSTC y la CGT, sus motivaciones estaban en la situación de carestía que campeaba, las altas cifras de desempleo y la negativa del gobierno del presidente López Michelsen de negociar los pliegos laborales. El 14 de septiembre se desarrollaron paros laborales de trabajadores petroleros, cementeros, de la palma y del magisterio que se oponían a la implementación del estatuto docente liderado por el Ministro Hernando Durán Dussán. En el apoyo del paro confluyeron los sectores de izquierda: Partido Comunista, MOIR y Unión Revolucionaria Socialista con el sector Ospino-Pastranista del Partido Conservador, una extrańa confluencia que solo se explica por el nuevo escenario post frente nacional (Celis, 2007).

En efecto, la represión del movimiento social durante el paro cívico engrosó el listado de presos políticos, que pasó en la cárcel La Modelo de 30 a 80. Este número tan significativo permitió la postulación de varios presos políticos para acceder a determinados cargos dentro de la prisión

11 Los presos con cierto grado de dominio utilizaban el secuestro de elementos personales, para luego cobrar por su entrega, también cobraban por espacios específicos para pernoctar o controlaban el microtráfico (Uribe y Trujillo, 1984). 
como los de ordenanzas, mensajeros o responsables de dependencias, elegidos por la misma administración penitenciaria. Esto facilitó la perspectiva organizativa y el movimiento de presos políticos por toda la cárcel, además de la accesibilidad a materiales (recursos educativos, legales, de salubridad, etc.), condiciones que contribuyeron para la edición de un primer documento de constitución interno de los presos políticos con las siguientes características:

a. Definición de preso político: extensión del concepto para algunos presos que, aunque no estaban en esta categoría desde la perspectiva jurídica, fueron incluidos; indígenas, sindicalistas, detenidos en el marco de las diferentes luchas, etc.

b. Integración organizativa para presos que no necesariamente eran políticos.

c. Las formas de coordinación entre grupos de presos políticos (Uribe y Trujillo, 1984).

Este documento fue enviado a varias cárceles con las cuales se tenía algún tipo de carteo, y se vinculó con otros procesos como el de la cárcel del Buen Pastor, único centro carcelario femenino de la capital.

\section{El papel de los familiares en la organización}

A pesar de las diferentes limitaciones que se dan en un encarcelamiento, los presos políticos y los primeros indicios de organización posibilitaron un ambiente diferente, que de hecho modificaba sentimientos y emociones, revitalizaba las relaciones de compañerismo, camaradería, unidad, disciplina y sencillez. Sumado a esto, la visita de los familiares proporcionaban nuevas provisiones alimentarias a los presos, generando un relacionamiento entre los familiares, y una nueva dinámica en la organización interior (Uribe y Trujillo, 1984).

En esa medida, los días de visita eran caracterizados por un aumento significativo de la comida y de ciertas provisiones elementales, lo que produjo la creación de una despensa colectiva, que permitió hacer una repartición horizontal y equitativa de las mismas.

Cabe resaltar la no exclusión de ningún preso partícipe de la organización por motivo de no contribución alimentaria hacia el grupo, y cuyo objetivo era que la despensa propiciara por un lado una alimentación complementaria a la ración carcelaria, y por el otro, el desdoblamiento de la disciplina mediante procesos de delegación como la creación de un ecónomo, a la par de forjar la integración familiar y la unidad (Uribe y Trujillo, 1984).

Así mismo fue significativo, en la potencialización de los presos políticos y su organización, la constitución de un Comité de Familiares de Presos Políticos (CFPP), el cual funcionaba como elemento de solidaridad mediante 
la denuncia constante de violaciones a los derechos de los detenidos y la búsqueda permanente de apoyo a otras organizaciones. Debido a determinados sectarismos insertos en los propios familiares, este comité contaba con un número reducido de participantes (Uribe y Trujillo, 1984).

Al parecer la organización de familiares de presos no era un fenómeno solamente en Bogotá,, los autores del Libro negro de la represión señalan la existencia de estos en el Valle del Cauca, además de las constantes protestas a los que este Comité se ve abocado contra las torturas en esta ciudad (Villegas y Rivas, 1980).

\section{Organización política en el centro penitenciario El Barne, la cárcel La Picota, y el contexto del M-19}

En cárceles como El Barne (Boyacá), floreció la organización de presos hacia finales del año 1978 y principios de 1979, con una convivencia de 26 presos políticos sumados a los 24 presos políticos entrantes, estos últimos sindicados de pertenecer al M-19, entre los cuales se incluía a Iván Mariano Ospina, quién 6 años más tarde sería jefe máximo de esa organización. Efectivamente el contexto de captura de los 24 presuntos guerrilleros del M-19 fue enmarcado en el robo de armas del Cantón norte el 31 de diciembre de 1978, considerado una de las operaciones más espectaculares de esta guerrilla, no solo por la capacidad estratégica que esta tuvo, sino por el golpe de opinión pública a nivel mundial, se hizio evidente la creatividad de dicha guerrilla y se ridiculizó la seguridad de las Fuerzas Militares ${ }^{12}$. Tras la operación, se despliega un enorme operativo militar por todo el país, con detenciones masivas, torturas y asesinatos, y la recuperación de las armas por parte de las Fuerzas Armadas colombianas dos meses más tarde ${ }^{13}$.

La ola represiva tras el golpe del Cantón Norte implicó el allanamiento de numerosas viviendas y la detención de cientos de personas sindicadas de pertenecer al M-19. Fueron varios los detenidos en Bogotá, Ibagué, Villavicencio, Bucaramanga, Cali, Medellín y otras ciudades. Además, se dan a conocer las diferentes torturas a las que son sometidos los sindicados, como "choques eléctricos, plantones de doce horas nocturnas, utilización

12 Se habla del robo de entre 5.000 y 7.000 armas de un depósito militar ubicado al norte de la ciudad de Bogotá.

13 El periodista Hollman Morris reconstruye este evento a partir de varios militantes partícipes directos de este operativo como Yamel Riaño, narrando lo siguiente: "Después de repartir las armas son meses duros porque en Bogotá queda columna y media y en Cali nos dan el golpe más contundente: cae Iván Marino y Nelly Vivas, mientras que Rosemberg Pabón está en Medellín. El trabajo se hace más intenso por esos meses, faltan cuadros militantes, ya que la mayoría está en las cárceles. La gente del Eme llega a prisión no tanto por la inteligencia del Ejército, sino por lo mucho de barbarie que fue el instrumento de la investigación. Los militares logran arrancar mucha información y generan, al interior de los presos, un sentimiento de desconfianza mutua por las delaciones arrancadas a punta de tortura. No sabíamos hasta dónde llegaba la infiltración del Ejército ni quienes estaban infiltrados o cuántos lo estaban y quiénes eran" (Morris, 2001). 
de caballos amaestrados para que muerdan a los sindicados, hundimientos en piscinas casi hasta la asfixia, amenazas de violación con escoba a las mujeres", entre otras (Villegas y Rivas, 1980).

En efecto, se crea así un ambiente social represivo y una arremetida nacional contra la insurgencia, lo que provocó el traslado a El Barne de 20 presos sindicados de auxiliar a las FARC, lo que permitió construir dinámicas organizativas dada la cantidad presos políticos, 70 en total.

(...) iniciamos ahora un lento y constructivo proceso de integración con todos estos compañeros de muy diversa formación y experiencia. Comenzó también el proceso de integración de nuestras familias (...) aprendieron a distribuir entre todos la comida y pequeños regalos que llevaban olvidados muchos años (...) la unidad de todo el grupo, el fondo común de alimentos, la elaboración conjunta de algunos alimentos nos fue a todos de enorme ayuda, pero particularmente a ellos (Uribe y Trujillo, 1984).

La colaboración de los presos sindicados ${ }^{14}$ de pertenecer al M-19 y debido a los medios con los que estos contaban al interior y en el exterior de la prisión, permitió la edición de dos mil copias de un artículo titulado Carta a un guardián, el cual explicaba el significado de preso político e intentaba quebrar la dinámica de amigo-enemigo con la guardia carcelaria, mostrándoles su propia condición como trabajadores y explotados por el sistema ${ }^{15}$, a la par que propiciaba una de las primeras acciones colectivas.

Para principios de 1980, específicamente el 26 de febrero se dio un hecho que impulsó y potenció la organización de presos políticos a nivel nacional, evidenció y visibilizó las condiciones políticas de los encarcelamientos, al igual que parte del conflicto armado interno, se da la toma a la embajada de la República Dominicana en Bogotá. Esta operación político-militar del M-19 fue una de las más grandes de esta organización, tuvo repercusiones a nivel nacional e internacional. La toma de la embajada dominicana por 16 guerrilleros inició con el secuestro de varios embajadores, cónsules, diplomáticos e invitados a la celebración efectuada en dicha embajada y llamó la atención mundial debido a la retención de altos cargos internacionales, además de convertirse en una acción política en territorio extranjero. El objetivo principal de la operación era la demanda de libertad de 311 presos políticos a cambio de los embajadores, 50 millones de dólares

14 El libro negro de la represión realiza un reporte específico sobre la cantidad de detenciones y la sistematización de estas como resultado del estado de sitio. El instrumento de la "sindicación" es utilizado por el Estado colombiano para establecer el encarcelamiento generalizado bajo "sospecha", lo que configuraba repercusiones sobre los sindicatos, los colectivos estudiantiles, las organizaciones sociales, periodistas, artistas hasta sacerdotes jesuitas etc., y desde allí la criminalización de huelgas, paros, manifestaciones. Los allanamientos, las detenciones y las torturas, fue denominado por el Comité de Derechos Humanos de la ONU como hechos de carácter "cotidiano" y como proceso de "Urugüayización", atendiendo a los procedimientos de dictadura en ese país (Villegas y Rivas, 1980, p. 255).

15 Uribe y Trujillo (1984) narran la relación de la publicación con algunos de los guardias: "El más interesado, muchas veces sucede esto, ha sido el guardián de más mala fama. Conversando con él parece persona compresiva" (p. 267). 
y el levantamiento del estado de sitio en Colombia. La toma de la embajada duraría desde el 27 de febrero hasta el 25 de abril y tendría consecuencias directas en los detenidos políticos, los cuales eran juzgados en Consejos de guerra.

La operación denominada "Libertad y democracia" cobijaba a elementos pertenecientes a otras organizaciones político-militares en Colombia ${ }^{16}$. En efecto, la combinación entre presos, cárceles y familiares posibilitaba la idea de una huelga carcelaria en las penitenciarías donde había presencia de los presos políticos, como acciones que respaldaran la toma de la embajada. La articulación inicial de la posible huelga se efectuaba por medio de mensajes que provenían desde Bogotá en la cárcel La Modelo:

(...) comunicarle la decisión de empezar una huelga de hambre que según un mensajero venido de Bogotá, iba a realizarse en todas las cáceles colombianas donde hubiera presos políticos, como respaldo a la embajada (...) después del momento que se tomaron la Capilla - sitio escogido para empezar la huelga (...) resistieron entre cinco y diez días los compañeros, finalmente vinieron las represalias con aislamientos (...) En ese punto los mensajes desde el interior de la embajada se hacían más inflexibles "vencer o morir, no nos iremos sin los presos (Uribe y Trujillo, 1984, pp. 143-144).

En cárceles como El Barne, la toma de la embajada fue recibida con esperanza por parte de los presos políticos, se inició una corta huelga de hambre que intentaba secundar las acciones del llamado a la huelga carcelaria en Bogotá. Sin embargo los mensajes no fueron efectivos y la huelga no tuvo mayores repercusiones a nivel nacional, hecho que fue más visible en la cárcel la Picota donde a pesar de los 300 presos políticos, no hubo acciones significativas.

La enorme cantidad de detenidos políticos en La Picota se debía a que allí se efectuaba uno de los juicios históricos contra el M-19, un Consejo de Guerra en el cual se juzgaba a un grueso de esta guerrilla, cuyos detenidos estaban hacinados en el patio primero y entre los cuales, se caracterizaba cuadros políticos como Andrés Almarales ${ }^{17}$.

16 La película La toma a la embajada (2000), dirigida por Ciro Durán, permite tener una idea gráfica sobre la necesidad principal de liberar los presos políticos como objetivo primario de dicha operación. Efectivamente, Rosemberg Pabón, -Comandante Uno- „,en su libro Así nos tomamos la Embajada, relata los hechos: "había estudiado numerosos casos de liberación de presos en otras partes del mundo y su investigación se encaminaba a recoger datos para montar una acción de toma de rehenes. Su equipo se concentró, pues, en dos objetivos: los clubes sociales y las embajadas. En poco tiempo descartaron la idea de los clubes y se dedicaron a recoger información sobre las fiestas a celebrarse en las embajadas que reúnen a numerosos políticos y representantes extranjeros. Entre las muchas sedes diplomáticas, Lucho se concentró en dos: la de la República Dominicana y la de Japón. La celebración de sus fiestas nacionales difería por tres meses y por eso quedó descartada la segunda" (Pabón, 1985, p. 24 ).

17 Andrés Almarales en su texto titulado Los trabajadores: sus luchas y sus organizaciones, escribe una síntesis elaborada en prisión el 21 de noviembre de 1979, fecha en que se da inicio al Consejo Verbal de Guerra contra miembros del M-19. En el libro relata en parte, como la cárcel La Picota se ha convertido en escuela de revolucionarios: "desde el principio mismo de nuestro cautiverio político insistimos en ir trasformando la penitenciaria en una tribuna de denuncias" (Almarales, 1992, p. 12). 
Figura 1. Fotografía del Consejo de Guerra del M-19. Con los brazos en alto los sindicados del M-19 entonan el himno nacional.

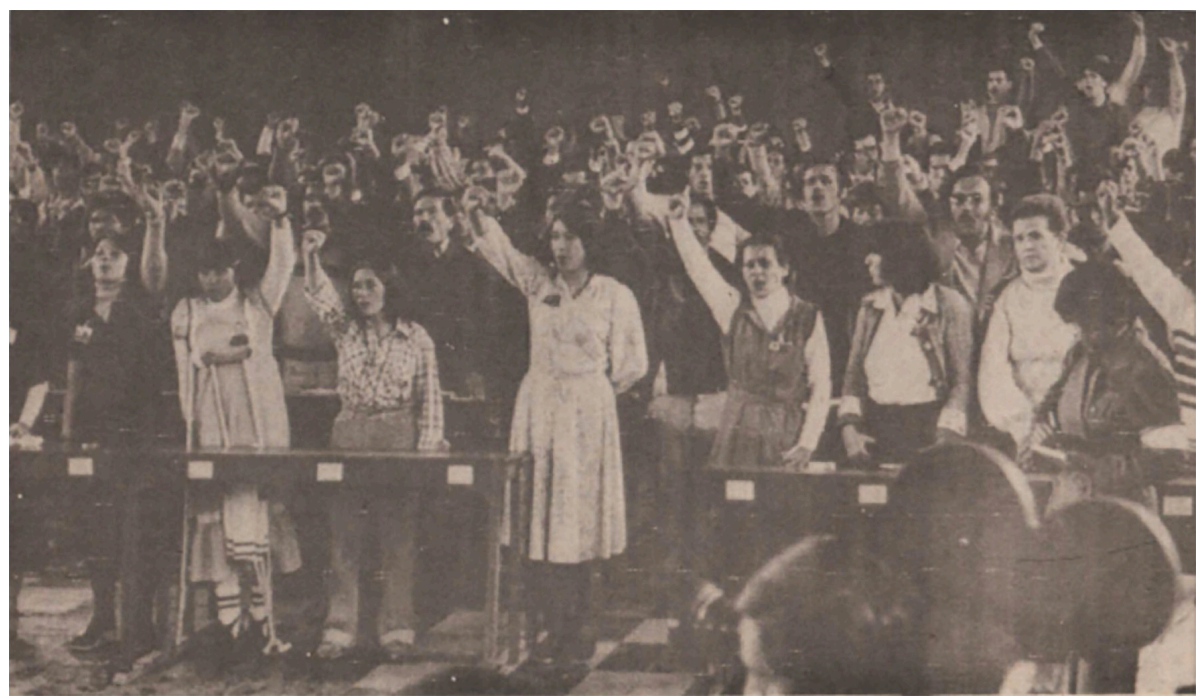

Fuente: Villegas y Rivas (1980, p. 262).

Para finales de abril, a pesar de la presión que la toma a la embajada ejercía sobre el gobierno, y los indicios de una huelga carcelaria fracasada ${ }^{18}$, las interacciones entre los presos políticos del M-19 y el resto de los patios era precaria, situación que fue transformándose gracias a las prácticas políticas y culturales realizadas por los presos, y a la minimización de conflictos entre las diferentes estructuras político-militares en actividades como el teatro o los deportes.

Los abogados, y con frecuencia también los militares que actúan como defensores de reos ausentes, juegan fútbol con los presos políticos. Esta fraternización es permanente. (...) Ahora los compas del M presentan una obra de teatro, a la que asisten algunos oficiales. La han iniciado con vivas a su organización (Uribe y Trujillo, 1984, p. 288)

Para principios de mayo de 1980, los comunicados de los dirigentes del M-19 advertían que la toma a la embajada tenía como objetivo "rescatar la democracia, denunciar las torturas y el estado de sitio" ${ }^{19}$, lo cual implicó

18 Es importante resaltar la huelga de hambre en la cárcel el Buen Pastor en solidaridad con la toma de la embajada (Villegas y Rivas, 1984, p. 257).

19 El 27 de abril de 1980 finaliza la toma a la embajada de la República Dominicana, con la liberación de los diplomáticos retenidos y el viaje de los guerrilleros del M-19 hacia Cuba. En términos específicos, la libertad de los presos políticos que era el objetivo central de la operación "democracia y libertad" nunca se cumplió. Al interior de las cárceles, los presos políticos mostraron cierta decepción, no solo por su incapacidad de secundar de una manera más contundente la acción, sino por las declaraciones de Jaime Bateman, líder del M-19: "El último comunicado de la dirección del M firmado por Jaime Bateman y Toledo Plata nos confunden más. Afirman que la operación de la embajada tuvo por objetivo recatar la democracia, denunciar las torturas y el estado de sitio." (Uribe y Trujillo, 1984, p. 292). Sin embargo, es fundamental aclarar que a partir de esta toma las propuestas sobre una amnistía general fueron tomando cuerpo. 
confusión al interior de las cárceles, pues el objetivo principal de la toma a la embajada había cambiado, esto desmoralizó a los detenidos en general, y creó incertidumbre en los propios líderes del M-19, Iván Marino Ospina y Andrés Almarales.

Las discusiones sobre el tema de la embajada fueron recurrentes entre todos los presos, y la reunión de todos los guerrilleros del M-19 en un solo patio permitió una gran movilización de experiencias; debates, formación política, integración y recreación, hasta la conformación de cuadros políticos. De la misma manera, la participación de los familiares era constante. En La Picota, los sábados y domingos se evidenciaban actos políticos, al igual que la permanente comunicación con líderes sociales, sindicales y estudiantiles, que en efecto, hacían de la cárcel La Picota un epicentro de actividades culturales, políticas y de organización con otros presos políticos pertenecientes a guerrillas como el Ejército Popular de Liberación (EPL) (Uribe y Trujillo, 1984).

Es necesario resaltar la participación de los familiares de los presos del M-19, al punto de constituir otro comité similar al que ya habían formado los otros familiares a principios de 1978, integrado solo por familiares de presos pertenecientes a esta organización y con un apoyo exclusivo a la misma (Uribe y Trujillo, 1984).

\section{La coordinadora de presos políticos de La picota y el inicio de la amnistía}

El trabajo generado por el nuevo comité de familiares y algunas rencillas presentadas en la cárcel La Picota, no solo por la participación numerosa de los presos del M-19, sino por su constante auto-referenciación (cánticos y vivas a esta organización todas las mañanas), dificultó la integración con la totalidad de presos políticos ${ }^{20}$. Esta dinámica se transformó a finales de 1980 y principios de 1981 debido a los acercamientos y afinidades entre los presos políticos de diferentes patios y organizaciones sociales y político-militares, que ampliaron los niveles de comunicación, minimizaron el factor autoreferencial y legitimaron otras organizaciones que no poseían "representantes" al interior de La Picota.

Estos pasos de organización integral se efectuaron gracias a la experiencia que habían conseguido varios de los presos en la penitenciaría de El Barne meses antes, y que ahora intentaba gestarse en La Picota. En efecto esta organización incluyó a los presos del M-19, dada la importante propuesta de esta guerrilla sobre una posible amnistía.

20 En 1980 ocurren dos hechos importantes, en julio se fugan algunos presos del M-19, lo que desata una persecución de orden nacional y días después se crea el delito de parentesco como forma en principio de frenar el apoyo efectuado por los comités de familiares, y segundo como forma de "retaliación" estatal. Para ejemplificar, en ese mismo año se celebraba en el Valle del Cauca un foro para tratar temas carcelarios, con una gran asistencia de familiares de presos políticos, varios de ellos tras terminar el evento, fueron detenidos bajo la "sindicación" del delito de parentesco (Villegas y Rivas, 1980). 
En La Picota teníamos una serie de dificultades comunes y unas cuantas tareas conjuntas, en la calle. Sobre estos aspectos era que debíamos ponernos de acuerdo. El proyecto de amnistía, presentado por el gobierno en respuesta a la campaña iniciada por el M-19, sirvió también de puente para el estrechamiento de relaciones entre la mayoría de los presos políticos. Unos cuantos de ellos, pertenecientes a las organizaciones PLA-EPL solo estuvieron de acuerdo en algunos aspectos parciales. El grupo de nuestro patio, conformado por detenidos del ELN, ADO y por un dirigente del M-19 (...) estaba integrado plenamente (Uribe y Trujillo, 1984, p. 301).

El trabajo de esta primera asociación entre los diferentes presos políticos en toda la cárcel La Picota también se desdobló hacia la consecución de provisiones, la discusión constante de documentos, la generación de acciones de tipo cultural y recreativo, la integración familiar en formas de solidaridad y apoyo como ya se venía realizando, hasta la generación de acciones reivindicativas y de fuerza como la paralización de actividades al interior de la cárcel, y cuyo objetivo era el mejoramiento de condiciones directas: prevención de las golpizas por parte de los guardias, trato a las visitas, restricción de movilidad de algunos presos y la creación de diálogos directos con la administración penitenciaria.

Estos temas y acciones facilitaron la creación de una coordinadora integrada por 4 representantes de los presos, cuyas funciones precisaban buscar el diálogo con la dirección del penal y reuniones periódicas con otros detenidos. Esta forma de coordinación era denominada Coordinadora de presos políticos, y su funcionamiento no precisaba ser una plataforma o partido donde se aglutinaban los presos políticos, sino que como su nombre lo indica, consistió y surgió a partir de acciones específicas y directas que contribuyeron al mejoramiento de las condiciones de todos los presos, a la medición de fuerzas de los presos políticos, como se evidenciaba en motines, y a la generación de cierto entusiasmo en otros presos no políticos, los cuales observaban positivamente los resultados prácticos que este tipo de acciones y asociaciones generaban.

El trabajo político implicó la transformación de la cotidianidad carcelaria:

Regresamos al pasillo y, a las dos, de nuevo reunión, tres veces por semana (...) análisis políticos de acontecimientos diarios; discusión de problemas especiales; relaciones con presos políticos de otros patios; control de actividades; crítica, autocrítica; selección de temas y responsabilidades para las obras de teatro o para los niños (Uribe y Trujillo, 1984, p. 308).

De hecho, el trabajo practicado por la coordinadora y por la unión de los presos políticos generaba la simpatía de los demás detenidos, como consecuencia de las prácticas políticas, éticas y acciones como el alejamiento de los vicios, el constante estudio, la disciplina, las actividades culturales y la "firmeza" contra los abusos de la guardia, se fortaleció la simpatía general y el crecimiento cuantitativo y cualitativo de colectivos de presos en los pasillos y patios.

La constancia en las actividades culturales (teatro, títeres, comedias), deportivas (ajedrez, fútbol), educativas (conferencias, charlas, cursos, 
periódico mural), políticas (mítines) e incluso actividades de cocina, daban una enorme dimensión a la coordinadora, que ahora incluía la participación de otros sectores como los indígenas (Uribe y Trujillo, 1984, p. 312).

Este tipo de prácticas continuaron hasta la consecución de la amnistía en 1982 como resultado de un diálogo nacional ${ }^{21}$, lo que permitió la salida de la mayoría de presos políticos ${ }^{22}$ y fue afianzada en el año 1985 con la Ley de indulto ${ }^{23}$. De esta manera concluía la primera etapa de la organización de presos políticos en las cárceles colombianas.

A pesar de las garantías generadas en esta amnistía como la finalización de los consejos verbales de guerra, nuevas tácticas como las operaciones cívico-militares, tuvieron un aumento exponencial en las diferentes zonas con presencia insurgente. ${ }^{24}$

Para finalizar, es fundamental resaltar que las prácticas organizativas de los presos políticos permitieron una trascendencia de lo ideológico a otros niveles como lo emocional, hasta el punto de mejorar anímica y moralmente a los presos, lo cual se veía reflejado en el cambio de actitud, su interacción con los otros presos, la calidez que se presentaba en sus acciones más humanitarias, el enriquecimiento cultural producto de sus experiencias y la constitución de la solidaridad como elemento esencial de las organizaciones.

21 Ley de Amnistía, Ley 35 de 19 de noviembre de 1982. Artículo 1. Concédese amnistía general a los autores, cómplices o encubridores de hechos constitutivos de delitos políticos cometidos antes de la vigencia de la presente Ley: Artículo 2. Para los efectos de esta Ley, entiéndase por delitos políticos los tipificados en el Código Penal como rebelión, sedición o asonada, y los conexos con ellos por haber sido cometidos para facilitarlos, procurarlos u ocultarlos; Artículo 3. Los homicidios fuera de combate no quedarán amparados por la amnistía si fueron cometidos con sevicia o colocando a la víctima en situación de indefensión o inferioridad, o aprovechándose de esta situación. (Congreso de la República, 1982).

22 Algunos de ellos continuaron detenidos por la configuración de otros delitos como homicidio.

23 Artículo 1. Autorízase al Presidente de la República para que, con base en las facultades que le confiere el ordinal cuarto del artículo 119 de la Constitución, conceda indultos con sujeción a las siguientes reglas: 1 . El indulto solo podrá cobijar a los condenados mediante sentencia ejecutoriada por los delitos de rebelión, sedición y asonada; 2. El indulto podrá extenderse a los delitos conexos con los anteriores, por haber sido cometidos para facilitarlos, procurarlos, consumarlos u ocultarlos, con excepción del secuestro, la extorsión, los delitos tipificados en el Decreto extraordinario 1188 de 1974 (estupefacientes) y el homicidio fuera de combate, si se hubiere cometido con sevicia o colocando a la víctima en situación de indefensión o inferioridad o aprovechándose de esa situación.

24 La cantidad de presos políticos liberados aun no es clara. En un informe del General Vega Uribe habla de una excarcelación de: 31 presos de las Farc; 265 del M-19; 35 del ELN; 6 del EPL; 30 del PLA; 6 de la ADO. Se hablaría de un total de 373 presos políticos. RAMÍREZ, Socorro y RESTREPO, Luís. Actores en conflicto por la paz. Siglo XXI editores. Bogotá, 1991, p. 95. 


\section{Conclusiones}

Son varios aspectos y componentes que han permitido la generación de organización y asociación de presos políticos en cárceles colombianas. En primer lugar el propio contexto político del país, las acciones de las organizaciones guerrilleras, los combates políticos de las organizaciones sociales y una emergente politización del sector campesino y sindical, incidieron de manera directa en los procesos de encarcelamiento de sujetos pertenecientes a las diferentes organizaciones.

La participación de estudiantes y de familiares de los presos (incluido los comités creados por estos), permitieron los primeros elementos de organización, que tuvieron como eje fundamental la solidaridad externa y las primeras formas de delegación de tareas internas. El contexto político creado por las diferentes acciones del M-19 y un aumento significativo de los presos, que devino en gran medida del impacto del estatuto de seguridad en 1978, convirtieron el escenario carcelario en una trinchera política, cultural y educativa, en un tribunal de denuncia, lo que generó el desdoblamiento de acciones concretas al interior de los centros carcelarios y hasta la constitución de una coordinadora de presos que integraba detenidos de diferentes vertientes políticas e ideológicas, todas situaciones que coadyuvaron en el proceso de amnistía e indulto como resultado de una negociación.

\section{Referencias}

Almarales, A. (1992). Los trabajadores: sus luchas y sus organizaciones: desde La Picota, un juicio antipatria. Medellín: Frente de investigaciones geopolítica de América Latina.

Celis, L. (Septiembre de 2007). El paro cívico de septiembre de 1977. Corporación Viva la ciudadanía. Recuperado de http://viva.org.co/cajavirtual/svc0079/ articulo07.pdf

Congreso de la República de Colombia (1982). Ley 35 de 19 de noviembre de 1982 por la cual se decreta una amnistía y se dictan normas tendientes al restablecimiento y preservación de la paz. Bogotá: Congreso de la República de Colombia.

Copel y APRE. (1977). Documentos de la lucha contra la cárcel. España: 1977. Recuperado de: https://boletintokata.files.wordpress.com/2012/02/copelapre_maquetacic3b3n-31.pdf

Entrevista al colectivo de prisioneros políticos Kamina Libre. (Agosto de 2006). Recuperado de http://www.alasbarricadas.org/noticias/node/3359

Galván, V. (2007). Sobre la abolición de las cárceles en la transición española. Revista HAOL, 14. 
Jiménez, C. (2009). Aplicación e instrumentalización de la doctrina de seguridad nacional en Colombia (1978-1982): efectos en materia de derechos humanos. Revista Colección, 20, p. 89.

Lorenzo, C. (2013). Cárceles en llamas. El movimiento de presos sociales en la transición. Barcelona: Virus editorial.

Medina, E., Sosa, J., Ventura, J. (Productores) y Duran, C. (2000). La toma a la embajada [Película]. Colombia: Producciones Ciro Durán.

Mesa, E. (2009). El Frente Nacional y su naturaleza antidemocrática. Revista Facultad de Derecho y Ciencias Politicas, 39(110). p. 159-184.

Morris, H. (2001). Operación Ballena Azul. Las armas del Cantón Norte. Bogotá: Editorial intermedio.

Pabón, R. (1985). Así nos tomamos la embajada. Bogotá: Editorial Planeta,

Paredes, Z. y Díaz, N. (2007). Los orígenes del Frente Nacional en Colombia. Revista de Historia, 12(23), pp. 179-190.

Pecaut, D. (1997). Presente, pasado y futuro de la Violencia. Revista Análisis político, 30, pp. 3-36.

Periódico Libelo. (Octubre de 1998). Boletín de información política desde la cárcel de alta seguridad. Periódico Libelo, 3.

Pont, D. (2008). Sobre la Copel. Por la memoria anticapitalista. España. Editorial Klinamen. 2008.

Presidencia de la República de Colombia (1978). Decreto 1923 de 1978 por el cual se dictan normas para la protección de la vida, honra y bienes de las personas y se garantiza la seguridad de los asociados. Bogotá: Presidencia de la República.

Ramírez, S y Restrepo, L. (1991). Actores en conflicto por la paz. Bogotá: Siglo XXI editores.

Restrepo, J. (Julio-diciembre de 2017). Actores sociales durante el gobierno de Alfonso López Michelsen, Colombia (1974-1978). Forum. Rev., 8(9), pp. 9-29

Santos, E. (18 de septiembre de 2011). Gabo y los años alternativos. Periódico el Tiempo. Recuperado de http://www.eltiempo.com/archivo/documento/ MAM-4832446.

Solar, F. (2007). Resistencia al interior de la cárcel de alta seguridad: la identidad en el Kolectivo Kamina Libre. Santiago de Chile: Universidad Academia de Humanismo Cristiano.

Uribe, M. y Trujillo, F. (1984). Desde adentro. Bogotá: Fundación Comité de Solidaridad con Presos Políticos.

Villegas, J. y Rivas, G. (1980). El libro negro de la represión 1958-1980. Bogotá: Editor FCSPP y FICA. 